\title{
Synthesis and photophysical characteristics of polyfluorene polyrotaxanes
}

\author{
Aurica Farcas ${ }^{*}$, Giulia Tregnago ${ }^{2}$, Ana-Maria Resmerita ${ }^{1}$, Pierre-Henri Aubert ${ }^{3}$ \\ and Franco Cacialli ${ }^{* 2}$
}

\author{
Full Research Paper \\ Address: \\ ${ }^{1}$ Supramolecular Chemistry Group, "Petru Poni" Institute of \\ Macromolecular Chemistry, Grigore Ghica Voda Alley, 700487-lasi, \\ Romania, ${ }^{2}$ London Centre for Nanotechnology and Department of \\ Physics and Astronomy University College London, Gower Street, \\ London WC1E 6BT, UK and ${ }^{3}$ Laboratoire de Physicochimie des \\ Polymères et des Interfaces (EA 2528), Institut des Matériaux, \\ Université de Cergy-Pontoise, F-95031 Cergy-Pontoise Cedex, \\ France \\ Email: \\ Aurica Farcas* - afarcas@icmpp.ro; \\ Franco Cacialli* - f.cacialli@ucl.ac.uk \\ * Corresponding author \\ Keywords: \\ energy band gaps; fluorescence lifetimes; permethylated \\ cyclodextrins; polyfluorene; polyrotaxanes \\ Beilstein J. Org. Chem. 2015, 11, 2677-2688. \\ doi:10.3762/bjoc. 11.288 \\ Received: 31 August 2015 \\ Accepted: 04 December 2015 \\ Published: 21 December 2015 \\ This article is part of the Thematic Series "Superstructures with \\ cyclodextrins: Chemistry and applications III". \\ Guest Editor: G. Wenz \\ (C) 2015 Farcas et al; licensee Beilstein-Institut. \\ License and terms: see end of document.
}

\begin{abstract}
Two alternating polyfluorene polyrotaxanes $(3 \cdot \mathbf{T M}-\mathbf{\beta C D}$ and 3·TM- $\gamma \mathbf{C D})$ have been synthesized by the coupling of 2,7-dibromofluorene encapsulated into 2,3,6-tri- $O$-methyl- $\beta$ - or $\gamma$-cyclodextrin (TM- $\beta C D$, TM- $\gamma \mathrm{CD}$ ) cavities with 9,9-dioctylfluorene-2,7diboronic acid bis(1,3-propanediol) ester. Their optical, electrochemical and morphological properties have been evaluated and compared to those of the non-rotaxane counterpart 3. The influence of TM- $\beta C D$ or TM- $\gamma$ CD encapsulation on the thermal stability,

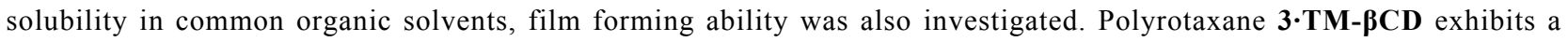
hypsochromic shift, while 3·TM- $\gamma$ CD displays a bathochromic with respect to the non-rotaxane $\mathbf{3}$ counterpart. For the diluted $\mathrm{CHCl}_{3}$ solutions the fluorescence lifetimes of all compounds follow a mono-exponential decay with a time constant of $\approx 0.6 \mathrm{~ns}$. At higher concentration the fluorescence decay remains mono-exponential for 3·TM- $\mathbf{\beta C D}$ and polymers 3 , with a lifetime $\tau=0.7 \mathrm{~ns}$ and $0.8 \mathrm{~ns}$, whereas the 3·TM- $\gamma \mathbf{C D}$ polyrotaxane shows a bi-exponential decay consisting of a main component (with a weight of $98 \%$ of the total luminescence) with a relatively short decay constant of $\tau_{1}=0.7 \mathrm{~ns}$ and a minor component with a longer lifetime of $\tau_{2}=5.4 \mathrm{~ns}(2 \%)$. The electrochemical band gap $\left(\Delta E_{\mathrm{g}}\right)$ of $\mathbf{3} \cdot \mathbf{T M}-\boldsymbol{\beta C D}$ polyrotaxane is smaller than that of $\mathbf{3} \cdot \mathbf{T M}-\boldsymbol{\gamma} \mathbf{C D}$ and $\mathbf{3}$, respectively. The lower $\Delta E_{\mathrm{g}}$ value for 3-TM- $\boldsymbol{\beta C D}$ suggests that the encapsulation has a greater effect on the reduction process, which affects the LUMO energy level value. Based on AFM analysis, 3·TM- $\mathbf{\beta C D}$ and 3·TM- $\boldsymbol{\gamma}$ CD polyrotaxane compounds exhibit a granular morphology with lower dispersity and smaller roughness exponent of the film surfaces in comparison with those of the neat copolymer 3 .
\end{abstract}




\section{Introduction}

Over the last decades, conjugated polymers (CPs) have been actively investigated as an alternative to conventional inorganic materials in many electronic applications due to their low cost and easy processability [1-6]. Among the various CPs, polyfluorenes (PFs) have been intensively studied as emitting materials owing to their pure blue emission [7-11]. However, some major drawbacks for their use are their high ionization potential associated with low photoluminescence (PL) efficiency, their rather large band gap and facile photochemical degradation [12,13]. Different strategies have been employed in view to reduce these undesirable effects, e.g., the synthesis of copolymers [14-17], block copolymers [18], the introduction of donor (D) and acceptor (A) moieties [19-21], or bulky substituents at the C-9 position of the fluorene units [22-24], incorporating PF moieties into zeolites [25], nanochannels [26], or by wrapping with amylose [27]. The past decade has witnessed remarkable innovations and progress in polymer science, including the field of supramolecular science as a complementary field, which offers great opportunity for new concepts, new materials with unique properties, and novel practical applications. The construction of polyrotaxane architectures has an impact on the polymer-chain behavior and subsequently generates smart functional polymeric materials [28-31]. Polyrotaxanes with conjugated polymers have attracted considerable attention over the last decades due to their architectures and topologies, but mostly because they provide an efficient strategy to achieve an "insulation" of individual molecular wires [30]. Additionally, the synthesis of such structures makes it possible to tune a large number of physicochemical properties of conjugated polymers [16-20,26-38]. The first step in the preparation of conjugated polyrotaxanes is the threading of macrocyclic compounds (hosts) onto linear chains (guests), when a thermodynamically unstable inclusion complex (IC) is obtained. A wide variety of host molecules have the ability to encapsulate the $\pi$-conjugated backbones into their cavities based on intermolecular interactions, and thus leading to ICs. Cyclodextrins (CDs) are by far the most intensively investigated macrocyclic molecules in the synthesis of such supramolecular architectures [39]. The second most investigated group of host molecules in the synthesis of conjugated polyrotaxanes is comprised of chemically-modified CDs. They are less hydrophilic than native CDs, and should exhibit a significantly increased ability to bind aromatic guests through ionic, ion-dipole, as well as hydrophobic interactions. CD liphophilic derivatives are more soluble in non-polar solvents and water and exhibit lower propensity to aggregate than native CDs [40-42]. Considering that larger hydrophobic CD surfaces can lead to increased interactions with the hydrophobic aromatic guest, several types of permodified $\mathrm{CD}$ derivatives, such as 2,3,6-tri- $O$-methyl- $\beta \mathrm{CD}$ (TM- $\beta \mathrm{CD})$ or 2,3,6-tri- $O$ - methyl- $\gamma \mathrm{CD}(\mathrm{TM}-\gamma \mathrm{CD})$ have been synthesized in the course of our investigations.

With a view to better understand the influence of TM- $\beta C D$ and TM- $\gamma$ CD encapsulations on the photophysical properties of PF, poly[2,7-(9,9-dioctylfluorene)-alt-2,7-fluorene/TM- $\beta C D)]$

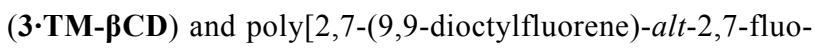
rene/TM- $\gamma$ CD)] $(\mathbf{3} \cdot \mathbf{T M}-\boldsymbol{\gamma} \mathbf{C D})$ polyrotaxanes have been synthesized. Thus, 3·TM- $\boldsymbol{\beta C D}$ and $3 \cdot \mathbf{T M}-\boldsymbol{\gamma} \mathbf{C D}$ have been obtained through the Suzuki cross-coupling reaction of 2,7-dibromofluorene (1) encapsulated into TM- $\beta C D$ or TM- $\gamma$ CD cavities (1·TM- $\boldsymbol{\beta C D}$ and $\mathbf{1} \cdot \mathbf{T M}-\boldsymbol{\gamma} \mathbf{C D})$ with 9,9-dioctylfluorene-2,7-diboronic acid bis(1,3-propanediol) ester (2), as bulky stopper units [43]. The thermal, surface morphology, optical as well electrochemical characteristics of both polyrotaxanes were compared to those of the non-threaded 3 counterpart, Scheme 1.

\section{Results and Discussion}

In continuation of our interest on the exploration of photophysical properties of PF copolymers by supramolecular encapsulation, we have performed the present study by using liphophylic CD derivatives, such as TM- $\beta C D$ and TM- $\gamma C D$ instead native

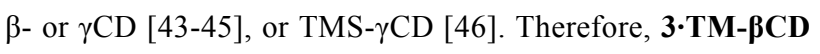
and 3-TM- $\gamma$ CD polyrotaxanes were synthesized by Suzuki coupling of $\mathbf{1}$ being in the form of its IC (1·TM-BCD or 1·TM$\gamma$ CD) with 2 followed by the termination of the growing chains by bromobenzene, Scheme 1 . To have the reference the neat copolymer $\mathbf{3}$ was also synthesized by coupling $\mathbf{1}$ with $\mathbf{2}$ under similar reaction conditions (Scheme 1).

TM- $\beta C D$ and TM- $\gamma$ CD macrocyclic molecules were prepared according to previously reported procedures [47]. 1·TM-BCD and 1-TM- $\gamma$ CD were synthesized in water by using a 2:1 molar ratio of macrocycles and monomer $\mathbf{1}$. The synthesis of 1-TM-BCD or 1-TM- $\gamma$ CD in polar protic solvents is driven by hydrophobic interactions in combination with electrostatic, van der Waals or $\pi-\pi$ interactions. In comparison, in polar aprotic solvents such as DMF, THF relies mostly on host-guest specific interactions, such as dispersion or dipole-dipole interactions.

As results of the encapsulation into TM- $\beta C D$ and TM- $\gamma C D$ cavities compared to native CDs [43-45], i.e., the use of toluene as solvent medium instead of a 3:1 v/v toluene/DMF mixture led to compounds soluble in toluene, THF, $\mathrm{CH}_{2} \mathrm{Cl}_{2}$ (DCM), and $\mathrm{CHCl}_{3}$. 3-TM- $\mathbf{\beta C D}$ due to its higher coverage showed 7\% water solubility. In addition, better optical quality films could be prepared by spin-coating from $3 \cdot \mathbf{T M}-\boldsymbol{\beta C D}$ and $\mathbf{3} \cdot \mathbf{T M}-\boldsymbol{\gamma} \mathbf{C D}$ THF, DCM, and $\mathrm{CHCl}_{3}$ solutions. 


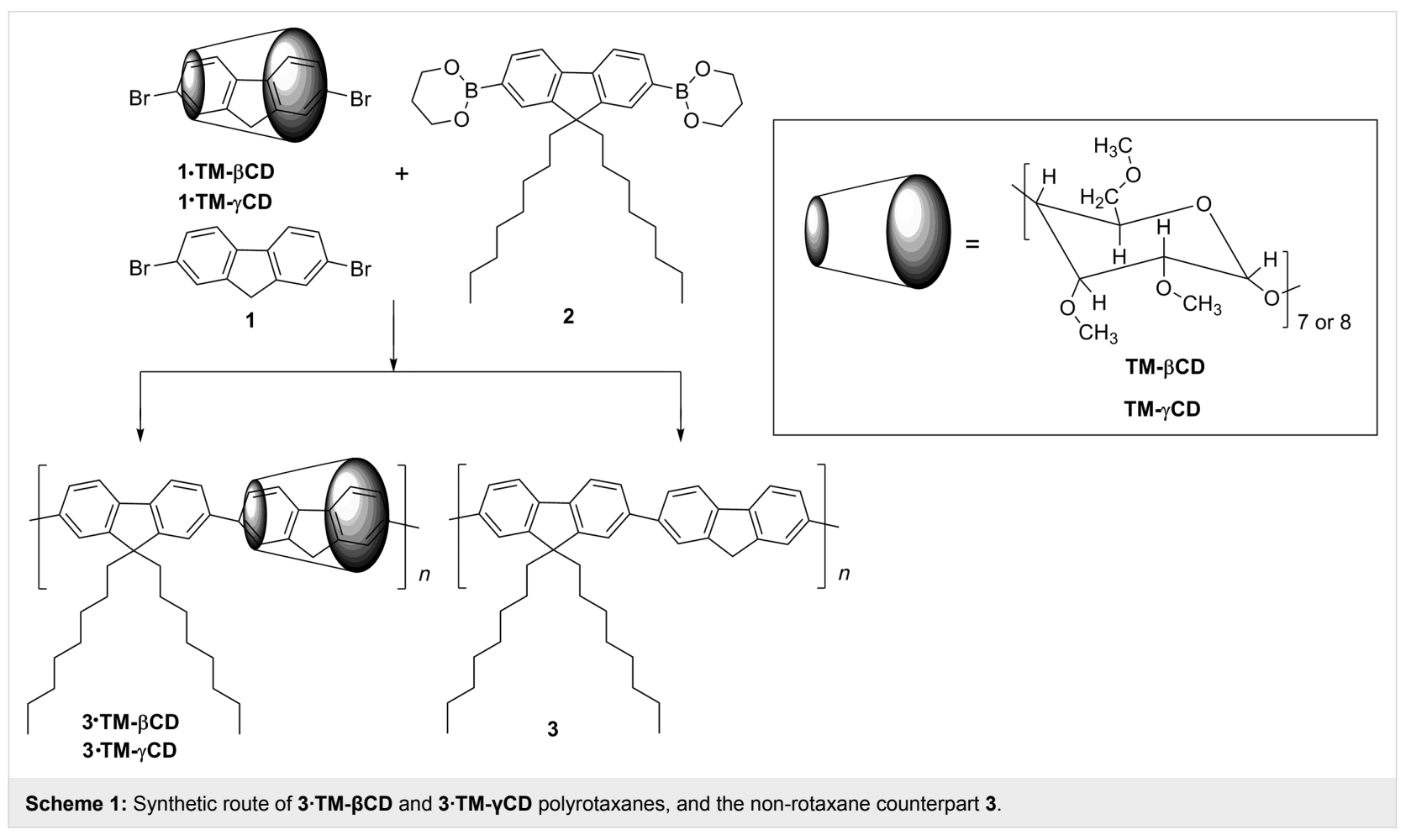

The investigated guest 1 proved binding ability to the hosts TM- $\beta C D$ and TM- $\gamma C D$, according to our determination of constant stability $\left(K_{\mathrm{S}}\right)$, which was performed by UV-vis absorption in $\mathrm{CHCl}_{3}$. Changes in the absorption intensity of $\mathbf{1}$ at $321 \mathrm{~nm}$ in the presence of increasing concentrations of TM- $\beta C D$ or TM- $\gamma$ CD provides the values of $K_{\mathrm{s}}$, Figures S1 and $\mathrm{S} 2$ in Supporting Information File 1. The analysis data shows that $K_{\mathrm{S}}$ could be approximately around $580 \pm 100$ and $160 \pm 30 \mathrm{M}^{-1}$ for $\mathbf{1} \cdot \mathbf{T M}-\boldsymbol{\beta C D}$ and $\mathbf{1} \cdot \mathbf{T M}-\boldsymbol{\gamma C D}$, respectively. $K_{\mathrm{S}}$ values of TM- $\beta C D$ encapsulation were higher than that of $\mathrm{TM}-\gamma \mathrm{CD}$, due to its more favorable dimensional compatibility.

Characterization of these compounds has been performed using FTIR and NMR spectroscopy. Figure S3 in Supporting Information File 1 gives the FTIR spectra of both polyrotaxanes and the reference 3. FTIR of encapsulated compounds 3-TM-BCD and 3-TM- $\gamma \mathbf{C D}$ reveals a distinct vibration peaks located in $1159-1042 \mathrm{~cm}^{-1}$ region due to the presence of TM- $\beta C D$ or TM- $\gamma C D$, whereas the reference 3 does not show any absorption peaks in this interval. Consequently, the disappearance of the characteristic peaks in $1159-1042 \mathrm{~cm}^{-1}$ region in the FTIR spectrum of reference 3 evidences the presence of macrocycles

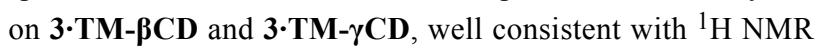
results.

As expected, the ${ }^{1} \mathrm{H}$ NMR spectrum of 3·TM-BCD polyrotaxane exhibits correlation peaks of both $\mathrm{H} 3$ and $\mathrm{H} 5$ protons of TM- $\beta C D$ with those methylene protons $\left(\mathrm{H}_{\mathrm{d}}\right)$ protons of mono- mer 2, and all the characteristic protons have been identified, Figure 1. Figures S4-S7 in Supporting Information File 1 show the ${ }^{1} \mathrm{H}$ NMR and ${ }^{13} \mathrm{C}$ NMR spectra of 3·TM- $\gamma \mathbf{C D}$ and the reference 3 .

The resonance peak of the $\mathrm{d}$ proton from monomer $\mathbf{2}$ is upfield shifted by more than $0.06 \mathrm{ppm}$ in the polyrotaxane $\mathbf{3} \cdot \mathbf{T M - \beta C D}$ compared to those of the non-rotaxane $\mathbf{3}$ counterpart, as shown in Figure 1 and Figure S4 in Supporting Information File 1. The resonance peaks of $a-c$ and $a^{\prime}-c$ ' protons of $\mathbf{3} \cdot \mathbf{T M - \beta C D}$ rotaxane copolymer are also upfield shifted by $0.05 \mathrm{ppm}$ as compared to those of the non-rotaxane homologue, while all protons of the TM- $\beta C D$ macrocycle are shifted by more than $0.07 \mathrm{ppm}$. Comparing the integrals of $\mathrm{d}$ ' protons from monomer 1 to those corresponding to $\mathrm{H} 1$ protons of TM- $\beta C D$, the average number of coverage per repeating unit has been calculated. By using the ratio of the integrated area of the H1 from TM- $\beta C D$ (5.13-5.12 ppm, $\left.\mathrm{I}_{\mathrm{H}-1}\right)$ and the methylene proton peaks of the monomer 1 (4.11-4.09 ppm, $\left.\mathrm{I}_{\mathrm{d}^{\prime}}\right) ;\left(\mathrm{I}_{\mathrm{H}-1} / 7\right) /\left(\mathrm{I}_{\mathrm{d}}, / 2\right)$ the coverage ratio was found to be of about 0.26 (i.e., ca. $26 \%$ coverage) suggesting that about every three structural unit was threaded with TM- $\beta C D$ macrocycle. However, compared with native CD $[43,45],{ }^{1} \mathrm{H}$ NMR results suggest poor hydrophobic-hydrophobic interactions of molecule 1 towards TM- $\beta C D$. Unfortunately, as a consequence of the low $K_{\mathrm{S}}$ of $\mathbf{1} \cdot \mathbf{T M}-\gamma \mathbf{C D}$, the polyrotaxane 3-TM- $\gamma$ CD presented only $11 \%$ coverage. The physical properties of the investigated copolymers are listed in Table 1 . 


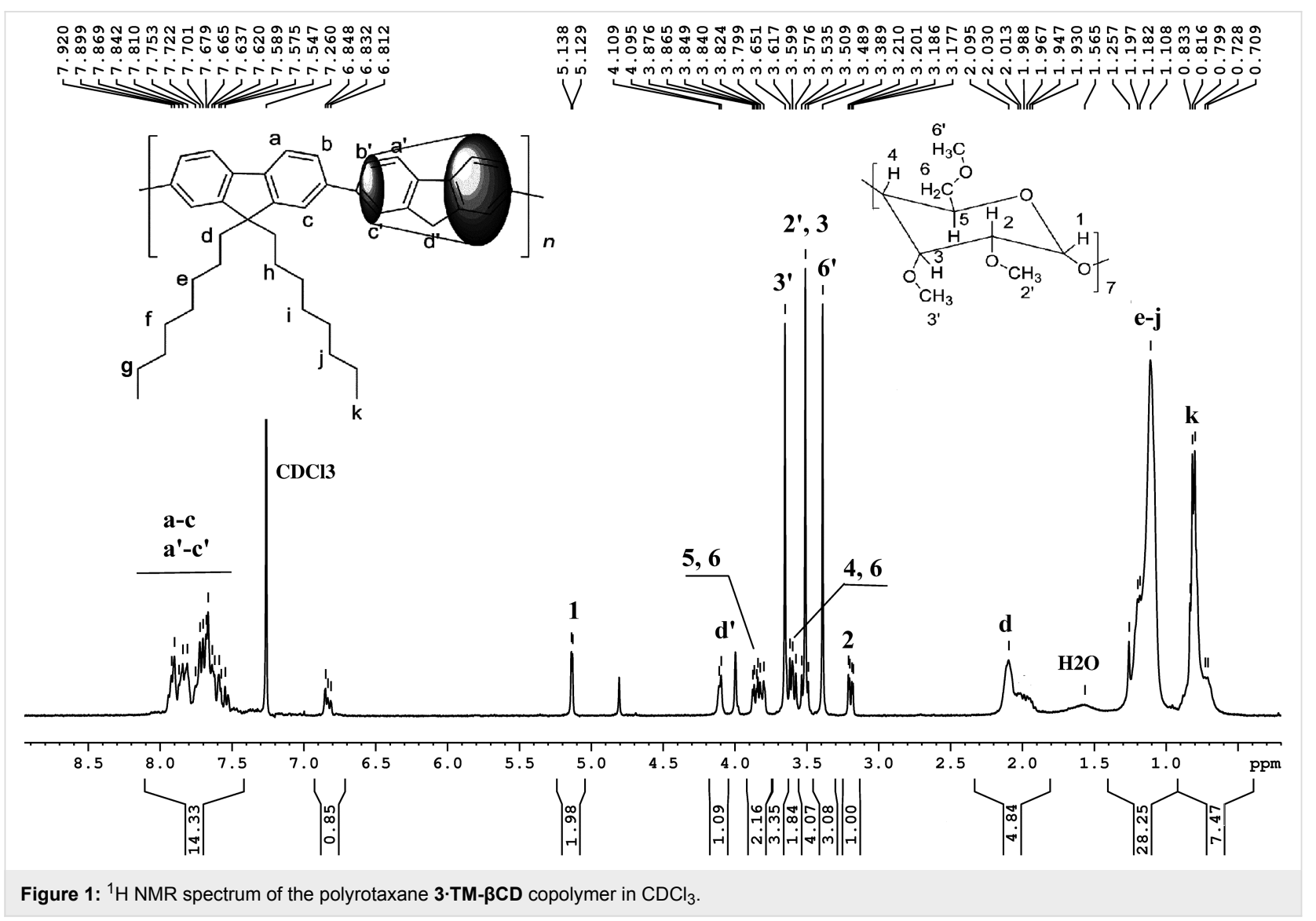

\begin{tabular}{|c|c|c|c|c|}
\hline Sample & $M_{\mathrm{n}}{ }^{\mathrm{a}}$ & $M_{\mathrm{w}} / M_{\mathrm{n}}^{\mathrm{b}}$ & Coverage $^{\mathrm{C}}(\%)$ & $T_{\mathrm{g}}{ }^{\mathrm{d}}\left({ }^{\circ} \mathrm{C}\right)$ \\
\hline 3 & 27900 & 1.83 & - & 88 \\
\hline 3·TM- $\beta C D$ & 24300 & 1.94 & 26 & 104 \\
\hline 3.TM-yCD & 20100 & 2.24 & 11 & 96 \\
\hline
\end{tabular}

aNumber average molecular weight determined by GPC, THF, Polystyrene (Pst) standards. ${ }^{\mathrm{b}}$ Polydispersity index. ${ }^{\mathrm{C}}$ Average number of macrocycles /structural units, determined from ${ }^{1} \mathrm{H}$ NMR analysis. ${ }^{\mathrm{d}}$ Glass-transition temperature estimated from the second-heating DSC measurements.

The polydispersity index $\left(M_{\mathrm{w}} / M_{\mathrm{n}}\right)$ and molecular weight distributions $\left(M_{\mathrm{n}}\right)$ of polymers obtained by gel permeation chromatography (GPC) analysis using Pst standards and THF as eluent, are presented in Table 1. Two things should be noted here concerning the lower $M_{\mathrm{n}}$ of 3·TM-BCD and 3-TM- $\boldsymbol{\gamma}$ CD polyrotaxanes than that of the neat copolymer 3. Firstly, the less ability of ester groups from molecule $\mathbf{2}$ to partially penetrate the macrocyclic cavities in the condensation reaction due to the sterical hindrance of methyl groups [48]. Secondly, could be assigned to the differences of the hydrodynamic radii of the polyrotaxane rod-like backbones and standards. Furthermore, the polarity and backbone stiffness of polyrotaxanes can deviate strongly from those of Pst. The higher $M_{\mathrm{w}} / M_{\mathrm{n}}$ of $\mathbf{3} \cdot \mathbf{T M}-\boldsymbol{\beta C D}$ and 3.TM- $\gamma$ CD polyrotaxanes than that of $\mathbf{3}$ non-rotaxane sample was assigned to the different content of threaded $\mathrm{TM}-\beta \mathrm{CD}$ or TM- $\gamma \mathrm{CD}$ on the copolymer chains (see incomplete coverage determined by ${ }^{1} \mathrm{H}$ NMR).

The thermal properties of the copolymers were evaluated by differential scanning calorimetry (DSC) and thermogravimetric analysis (TGA). All copolymers showed only glass-transitions $\left(T_{\mathrm{g}}\right)$ and not any exothermal crystallization peak characteristic of polymers containing 9,9-dioctyl-2,7-fluorene units (PFO) [49], Figure 2.

The non-rotaxane copolymer 3 has a $T_{\mathrm{g}}$ at $88^{\circ} \mathrm{C}$. The $T_{\mathrm{g}}$ value increases for 3· TM- $\gamma$ CD and 3·TM-BCD to $96{ }^{\circ} \mathrm{C}$ and $104{ }^{\circ} \mathrm{C}$, with respect to that of the non-rotaxane counterpart. The threading of $\mathbf{1}$ backbone through the cavities gives a more rigid copolymer structures with increased $T_{\mathrm{g}}$, as results of its encapsulation, Table 1. It should be mentioned, that increased threading leads to a higher $T_{\mathrm{g}}$ of the resulting $3 \cdot \mathbf{T M}-\boldsymbol{\beta C D}$ polyrotaxane. The thermal stability of the copolymers was also investigated by TGA (not shown) and the TGA data revealed that all polymers were stable up to about $300{ }^{\circ} \mathrm{C}$. 


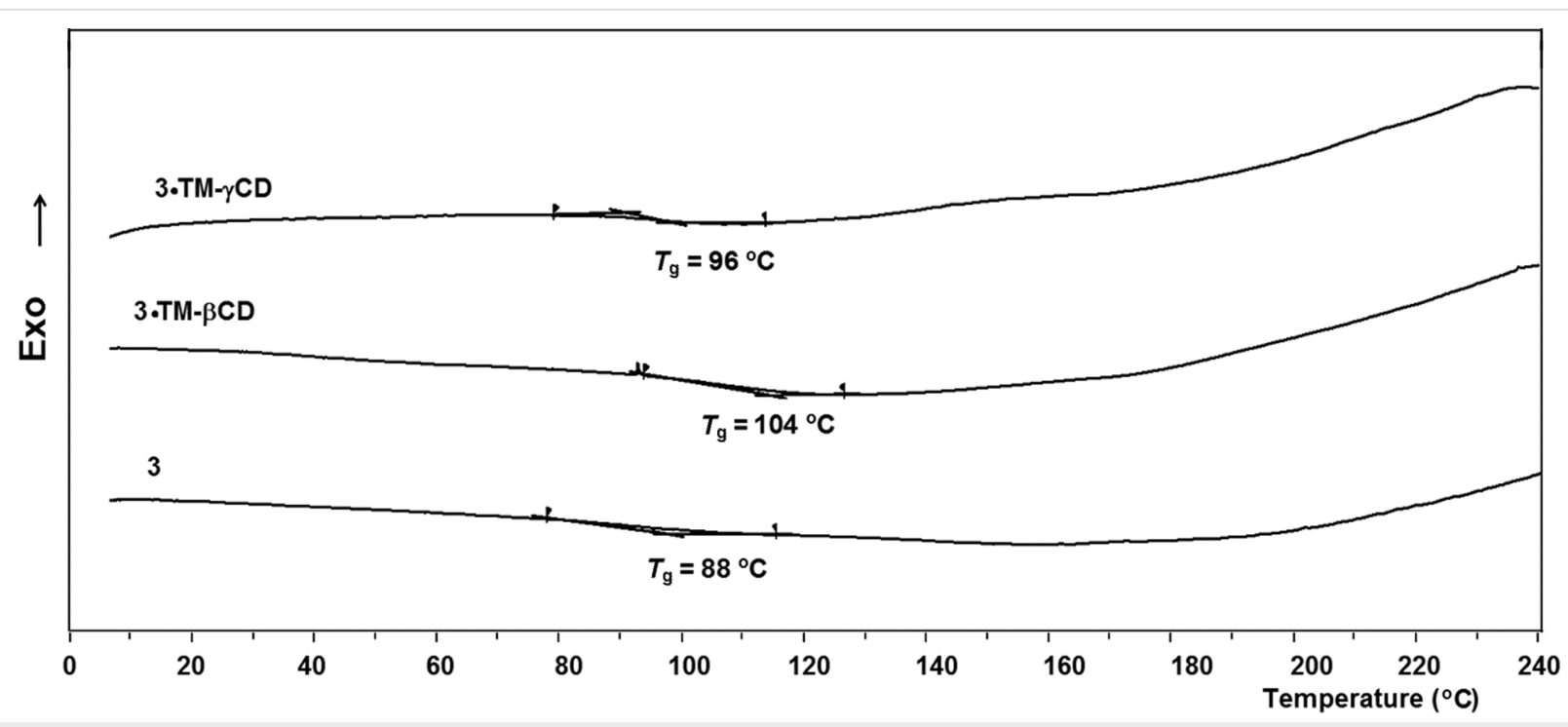

Figure 2: DSC traces on second heating scan of 3, 3-TM- $\beta$ CD and 3-TM-үCD compounds.

The absorption spectra of $\mathbf{3} \cdot \mathbf{T M}-\boldsymbol{\beta C D}$ and $\mathbf{3} \cdot \mathbf{T M}-\boldsymbol{\gamma} \mathbf{C D}$ polyrotaxanes and the unthreaded 3 counterpart at a concentration of $10^{-1} \mathrm{mg} \cdot \mathrm{mL}^{-1}$ in $\mathrm{CHCl}_{3}$ are reported in Figure 3a. The nonrotaxane 3 copolymer shows a featureless band peaking at $374 \mathrm{~nm}$. Upon encapsulation with the TM- $\beta C D$, we note a hypsochromic shift of about $7 \mathrm{~nm}$ that can be attributed to a reduction of intermolecular interactions and/or a variation of the polarity when the PF core is inside the macrocycles' cavity. The 3-TM- $\gamma$ CD polyrotaxane copolymer, instead, displays a redshift of about $8 \mathrm{~nm}$ thereby suggesting the presence of some intrachain species. We consider such a red-shift however, not to be sufficient to infer the presence of fluorenone defects [24], although clear spectroscopic signature of the presence of such species can be gleaned from time-resolved photoluminescence efficiency (PL) experiments.
The PL spectra of the copolymers in $\mathrm{CHCl}_{3}$ solutions at a concentration of $10^{-1} \mathrm{mg} \cdot \mathrm{mL}^{-1}$ are reported in Figure $3 \mathrm{~b}$. The emission of the non-rotaxane 3 copolymer shows three vibronic components at about 418,435 and $460 \mathrm{~nm}$. The intensity of the $0-1$ fluorescence band $(435 \mathrm{~nm})$ for diluted $\mathrm{CHCl}_{3}$ solution is the most intense. At the same concentration, 3-TM- $\mathbf{\beta C D}$ exhibited a slight blue-shift $(2 \mathrm{~nm})$ of the emission. The ratio of the emission intensity of the $0-0$ transition for 3-TM-BCD is higher than that of the $0-1$ transition, contrary to what we observe for the non-rotaxane 3 counterpart. Such trends suggest that the encapsulation with the macrocycle TM- $\beta C D$ acts to reduce intermolecular interactions, in agreement with previous reported results [50]. Interestingly, $\mathbf{3} \cdot \mathbf{T M}-\boldsymbol{\gamma} \mathbf{C D}$ shows a much stronger $0-1$ transition than the $0-0$ one, as the non-rotaxane copolymer 3, which might be indicative of some aggregation even though

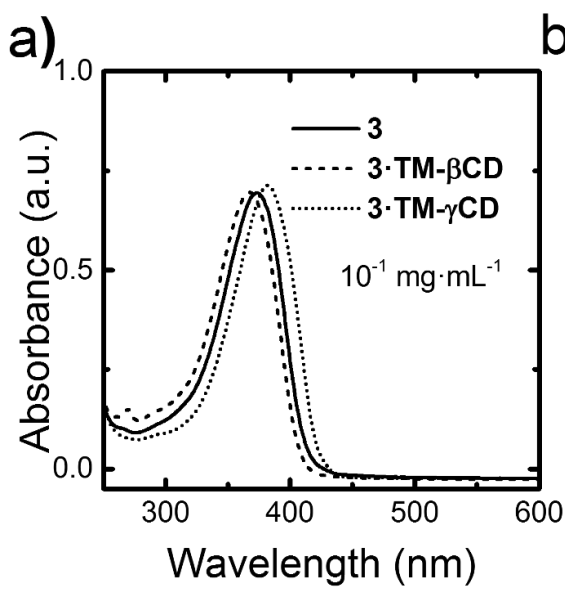

b)

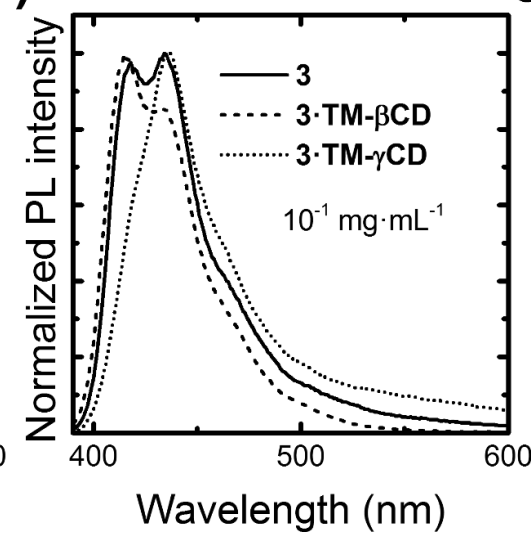

c)

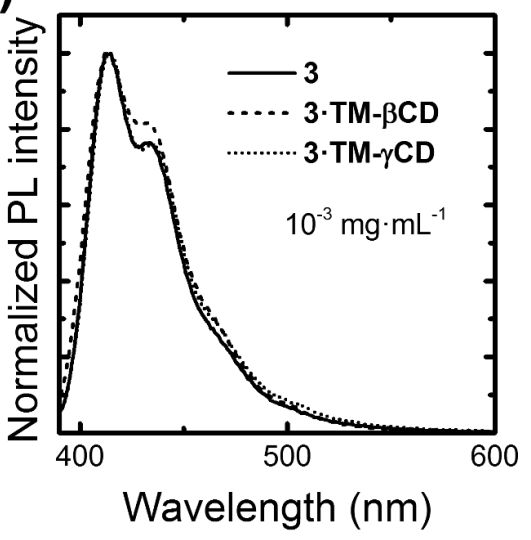

Figure 3: Optical properties of 3·TM-YCD (dotted line), 3-TM- $\beta$ CD (dashed line) and 3 (solid line) polymers: absorption spectra at $10^{-1} \mathrm{mg} \cdot \mathrm{mL}^{-1}$ in $\mathrm{CHCl}_{3}(\mathrm{a})$, and normalized emission spectra at $10^{-1} \mathrm{mg} \cdot \mathrm{mL}^{-1}$ and $10^{-3} \mathrm{mg} \cdot \mathrm{mL}^{-1}$ in $\mathrm{CHCl}_{3}$, (b) and (c), respectively. 
we do not observe a strong tail in the $500-600 \mathrm{~nm}$ regions (apart from the minor red-shift mentioned earlier). We also note that such TM- $\gamma$ CD threaded polyrotaxanes and the unthreaded polymer have a similar PL emissions with the $0-0$ the most intense transition for diluted solutions $\left(10^{-3} \mathrm{mg} \cdot \mathrm{mL}^{-1}\right.$ in $\mathrm{CHCl}_{3}$ ), as reported in Figure 3c. It appears that TM- $\beta$ CDs are much more effective than $\mathrm{TM}-\gamma \mathrm{CD}$ at suppressing intermolecular interactions upon an increase of the polymer concentration. Such interpretation is also corroborated by the time-resolved PL spectroscopy. Indeed, we find that the temporal decays for the diluted solutions are mono-exponential with a time constant of $\approx 0.6 \mathrm{~ns}$ for the polyrotaxanes and the non-rotaxane polymer at a concentration of $10^{-3} \mathrm{mg} \cdot \mathrm{mL}^{-1}$ in $\mathrm{CHCl}_{3}$. However, at a concentration of $10^{-1} \mathrm{mg} \cdot \mathrm{mL}^{-1}$ in $\mathrm{CHCl}_{3}$, while the decay is still mono-exponential for $\mathbf{3}$ and $\mathbf{3} \cdot \mathbf{T M - \beta C D}$ polymers ( $\tau \approx 0.7 \mathrm{~ns}$ and $0.8 \mathrm{~ns}$, respectively), $\mathbf{3} \cdot \mathbf{T M}-\boldsymbol{\gamma} \mathbf{C D}$ polymer shows a bi-exponential decay with $\tau$ of $0.7 \mathrm{~ns}$ and $5.4 \mathrm{~ns}$, with relative weights of 98 and $2 \%$, respectively. The longer $\tau$ for the 3-TM- $\gamma$ CD polyrotaxane is consistent with "interchain states". While these do not dominate the luminescence of the materials (the longer lifetime only accounts for $2 \%$ of the total PL weight), they are plausible, considered the significantly bigger size of the $\gamma \mathrm{CD}$, which might favor both unthreading of the cores, or even accommodation of more than one core unit within the macrocycles cavities. Poor suppression of interchain interactions by $\gamma \mathrm{CD}$ had already been observed in the case of diphenylenevinylene rotaxanes, and it is therefore not surprising that we observe similar effects [33].

Interestingly, we measure a photoluminescence quantum efficiency (PLQE) of $66 \pm 7 \%$ for the 3·TM- $\gamma \mathbf{C D}, 56 \pm 6 \%$ for the 3-TM-BCD and $46 \pm 5 \%$ for the reference 3 polymer. Given the relatively large errors in these measurements the only conclusion we can draw is that the unthreaded materials is slightly less efficient than 3-TM- $\gamma \mathbf{C D}$, but we consider we should not try to read too much into the difference in PL efficiency between 3·TM- $\gamma$ CD and 3·TM-BCD.

With a view to understand the factors that control the charge transport within and between conjugated macromolecular chains and the macrocycles, $\mathbf{3}, \mathbf{3} \cdot \mathbf{T M}-\boldsymbol{\beta C D}$ and $\mathbf{3} \cdot \mathbf{T M}-\boldsymbol{\gamma} \mathbf{C D}$ were electrochemically investigated by cyclic voltammetry (CV), Figure 4 and the results are summarized in Table 2. The $E_{\mathrm{p}, \text { onset }}$ and $E_{\mathrm{n} \text {,onset }}$ values allow the estimation of the ionization potential (IP), electron affinity (EA) and energy band gap $\left(\Delta E_{\mathrm{g}}\right)$ using ferrocene $(\mathrm{Fc})$ as reference [51]. The IP, EA energy levels and $\Delta E_{\mathrm{g}}$ were calculated according to Equations 1-3 $[52,53]$.

$$
E_{\mathrm{HOMO}}(\sim \mathrm{IP})=-\mathrm{e}\left(E_{\mathrm{p}, \text { onset }}-0.44\right)-4.80(\mathrm{eV})
$$

$$
\begin{gathered}
E_{\mathrm{LUMO}}(\sim \mathrm{EA})=-\mathrm{e}\left(E_{\mathrm{n}, \text { onset }}-0.44\right)-4.80(\mathrm{eV}) \\
\Delta E_{\mathrm{g}}=(\mathrm{EA}-\mathrm{IP})(\mathrm{eV})
\end{gathered}
$$

where: $-4.80 \mathrm{eV}$ represents the position of the $\mathrm{Fc}^{+} / \mathrm{Fc}$ redox couple in the energetic diagram $[51] ;+0.44 \mathrm{~V}$ is the redox potential of $\mathrm{Fc}^{+} / \mathrm{Fc}$ vs $\mathrm{Ag}$.

As indicated in Table 2, during the $n$-doping process, polyrotaxane 3-TM-BCD is reduced at a lower potential $(-1.71 \mathrm{~V})$ compared to the neat copolymer $\mathbf{3}$, and the polyrotaxane 3-TM- $\gamma$ CD, whose reduction potentials are attained at $-1.79 \mathrm{~V}$, and $-2.02 \mathrm{~V}$, respectively. The encapsulation of monomer 1 into TM- $\beta C D$ or TM- $\gamma C D$ cavities appears to have a greater effect on the LUMO energy levels of 3·TM-BCD and 3-TM- $\gamma$ CD polyrotaxanes. Furthermore, these results suggest that TM- $\beta C D$ may impose a more constrictive environment for the monomer 1 than $\mathrm{TM}-\gamma \mathrm{CD}$, due to its smaller inner cavity diameter. Consequently there is the possibility for TM- $\gamma \mathrm{CD}$ to move along on the monomer 1 backbone, until the stopper groups and these displacements to affect the LUMO energy level of the resulting 3.TM- $\gamma$ CD polyrotaxane, see Table 2. By contrast, TM- $\beta C D$ which is more localized on the monomer $\mathbf{1}$ backbone do not influence the LUMO energy level of 3·TMBCD compared to the reference 3. Obviously, the LUMO energy value is responsible for the low value of $\Delta E_{\mathrm{g}}$ in the case of 3-TM-BCD polyrotaxane. Note that the redox behaviors of the investigated polyrotaxanes have a similar origin with those of the reference copolymer 3. Close inspection of the electrochemical results suggest that all three investigated compounds exhibit typical semi-conducting properties, i.e., an insulating behavior in a wide range of potential between $n$ - and $p$-doping processes.

As shown by the CV in Figure 4, 3-TM- $\mathbf{B C D}$ exhibited three reduction peaks in the first $\mathrm{CV}$ scan at $0.0 \mathrm{~V}$ (very small), $-1.0 \mathrm{~V}$ and at $-1.8 \mathrm{~V}$, respectively. The last one corresponds to the $n$-doping process. The peaks from $0.0 \mathrm{~V}$ and $-1.0 \mathrm{~V}$ could be associated with the trapping of ionic charges into the polymer when the polymer returns to its neutral (insulating) state after the first CV scan, as previously reported [20]. Furthermore, these results suggest that the reduction process of 3-TM- $\boldsymbol{B C D}$ displays a semi-reversible behavior.

The HOMO/LUMO energy levels in combination with the electronic potentials of the anodic indium tin oxide (ITO) glass substrate $(-4.75 \mathrm{eV})$ and cathodic aluminum $(-2.2 \mathrm{eV})$, prove that the investigated compounds are electrochemically accessible as electron-transporting materials for fabrication of organic lightemitting diodes (OLEDs) [54], Figure 4d. 

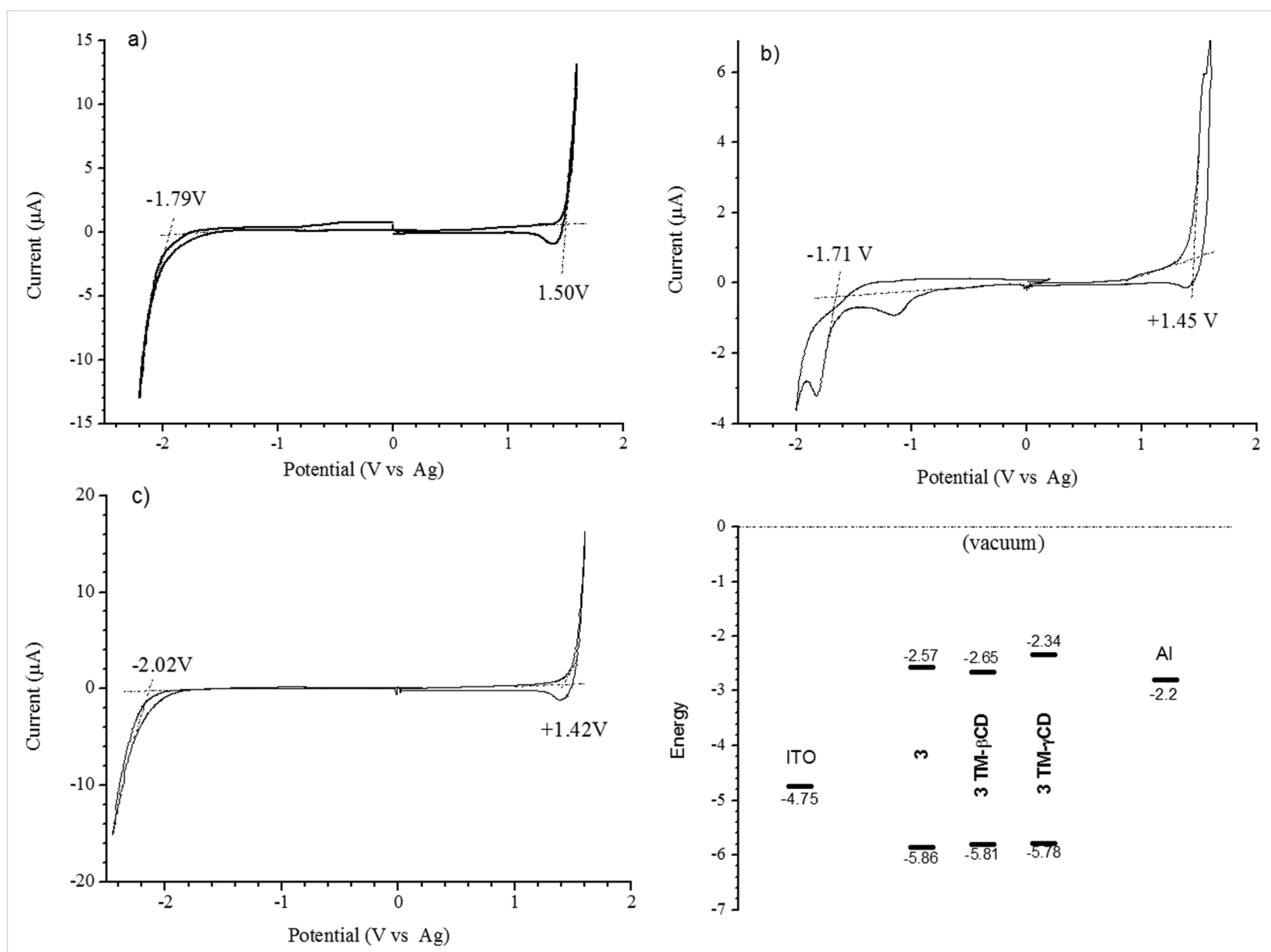

Figure 4: $C V$ of $3(a), 3 \cdot T M-\beta C D(b)$ and 3-TM- $\mathbf{Y} C D(c)$ in $0.1 \mathrm{M}$ tetrabutylammonium perchlorate $\left(\mathrm{TBACIO}_{4}\right) / \mathrm{ACN}$ solution at scan rate $20 \mathrm{mV} \cdot \mathrm{s}^{-1}$ and HOMO/LUMO energetic levels in addition to the work function of ITO (anode) and Al (cathode) (d).

Table 2: The electrochemical data for 3, 3-TM- $\beta$ CD and 3-TM-yCD copolymers.

\begin{tabular}{lccc} 
Sample & $\mathbf{3}$ & 3-TM- $\boldsymbol{B C D}$ & 3·TM-YCD \\
\hline Oxidation $^{\mathrm{a}}\left(E_{\mathrm{p}, \text { onset }}\right)(\mathrm{V})$ & 1.5 & 1.45 & 1.42 \\
Reduction $^{\mathrm{b}}\left(E_{\mathrm{n}, \text { onset }}\right)(\mathrm{V})$ & -1.79 & -1.71 & -2.02 \\
$E_{\mathrm{HOMO}} \approx \mathrm{IP}^{\mathrm{c}}(\mathrm{eV})$ & -5.86 & -5.81 & -5.78 \\
$E_{\mathrm{LUMO}} \approx \mathrm{EA}^{\mathrm{d}}(\mathrm{eV})$ & -2.57 & -2.65 & -2.34 \\
$\Delta E_{\mathrm{g}}^{\mathrm{e}}(\mathrm{eV})$ & 3.29 & 3.16 & 3.44 \\
\hline
\end{tabular}

a Oxidation onset potentials. ${ }^{\mathrm{b}}$ Reduction onset potentials. ${ }^{\mathrm{c}} E_{\mathrm{HOMO}}=-\mathrm{e}\left(E_{\mathrm{p}, \text { onset }}-0.44\right)-4.80 .{ }^{\mathrm{d}} E_{\mathrm{LUMO}}=-\mathrm{e}\left(E_{\mathrm{n}, \mathrm{onset}}-0.44\right)-4.80(\mathrm{eV})$. eElectrochemical band gap $\left(\Delta E_{\mathrm{g}}=E_{\mathrm{LUMO}}-E_{\mathrm{HOMO}}\right)$.

To gain further insights into the effect of macrocyclic encapsulations, it is also important to investigate the influence of the nature of host molecules on the induced chemical changes of the 3·TM- $\boldsymbol{\beta} C \mathbf{D}$ and $\mathbf{3} \cdot \mathbf{T M}-\boldsymbol{\gamma} \mathbf{C D}$ polyrotaxane surfaces. Advancing contact angles $(\theta)$ values of water (polar) and diiodomethane (apolar) have been obtained for spin-coated copolymer films, Table 3 . The smaller value of $\theta$ in water for 3.TM- $\gamma \mathbf{C D}\left(87^{\circ}\right)$ with respect to the non-rotaxane counterpart 3 $\left(100^{\circ}\right)$ reflects its higher hydrophilicity attributed to TM- $\gamma \mathrm{CD}$ encapsulation. A different behavior is observed for 3·TM-BCD which prevented any contact angle measurements. This phenomenon should be attributed to the better dissolution of the spin-coated film of 3.TM-BCD in water. As can be seen from Table 3, quite similar values were obtained in diiodomethane for the reference $\mathbf{3}$ and $\mathbf{3} \cdot \mathbf{T M}-\boldsymbol{\gamma} \mathbf{C D}$ polyrotaxane. These results are typical of surfaces covered with a close packing of hydro- 
Table 3: Advancing contact angle of water and diiodometane measured on spin-coated film of compounds.

\begin{tabular}{|c|c|c|}
\hline Sample & $\theta\left({ }^{\circ}\right)^{\mathrm{a}}$ & $\theta\left({ }^{\circ}\right)^{\mathrm{b}}$ \\
\hline 3 & $100.1 \pm 1.9$ & $49.9 \pm 0.3$ \\
\hline 3.TM- $\beta C D$ & $-^{c}$ & $43.5 \pm 0.7$ \\
\hline 3.TM-yCD & $87.3 \pm 1.7$ & $48.4 \pm 0.8$ \\
\hline
\end{tabular}

${ }^{a}$ Water advancing contact angle. ${ }^{\mathrm{b}}$ Diiodomethane advancing contact angle. 'Due to the dissolution of the spin-coated film, water advancing contact angles prevented any contact angle measurements. carbon chains [55]. In contrast, a lower $\theta$ value is observed for 3-TM-BCD. Such phenomenon represents a significant contribution of TM- $\beta C D$ high coverage.

To further explore the effect of the TM- $\beta C D$ and TM- $\gamma C D$ encapsulations, the surface topography of the copolymers was also investigated by atomic force microscopy (AFM) analysis. Some representative images obtained for the non-rotaxane $\mathbf{3}$,

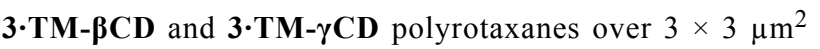
areas, are shown in Figure 5 and the results are summarized in Table 4. (a)

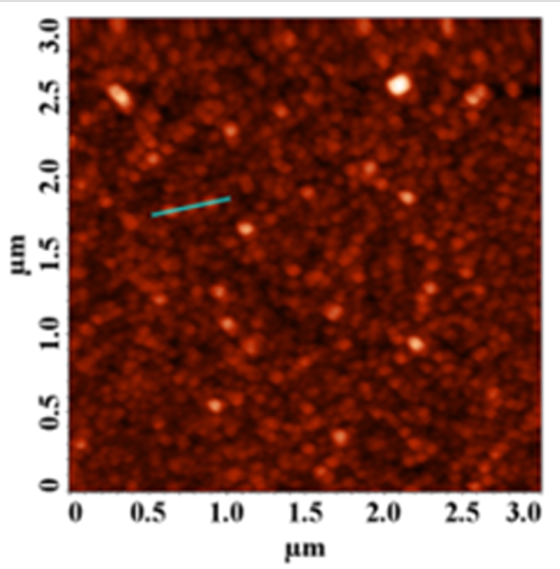

(b)

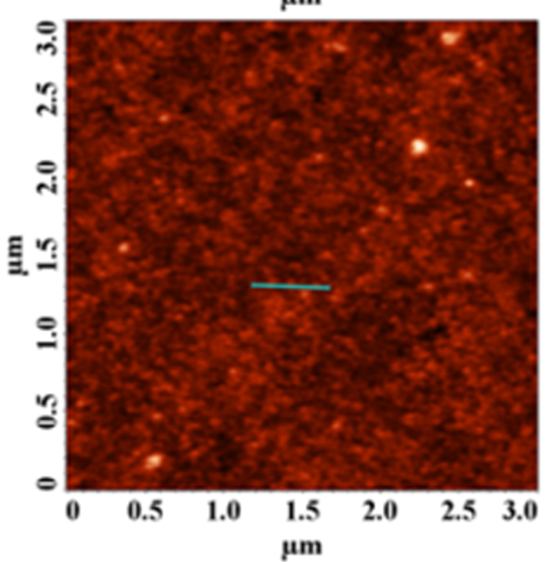

(c)

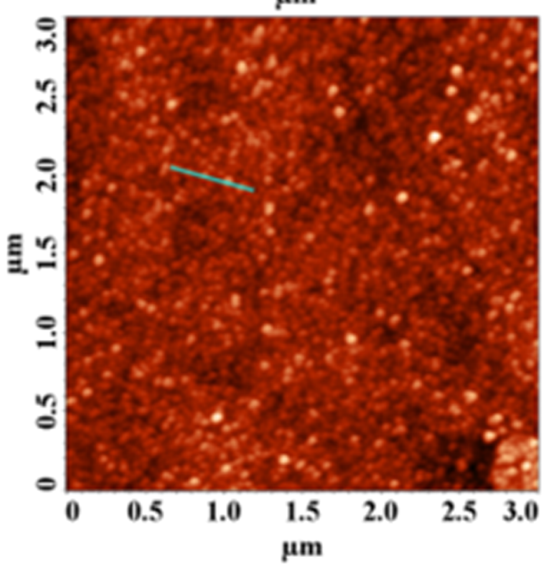

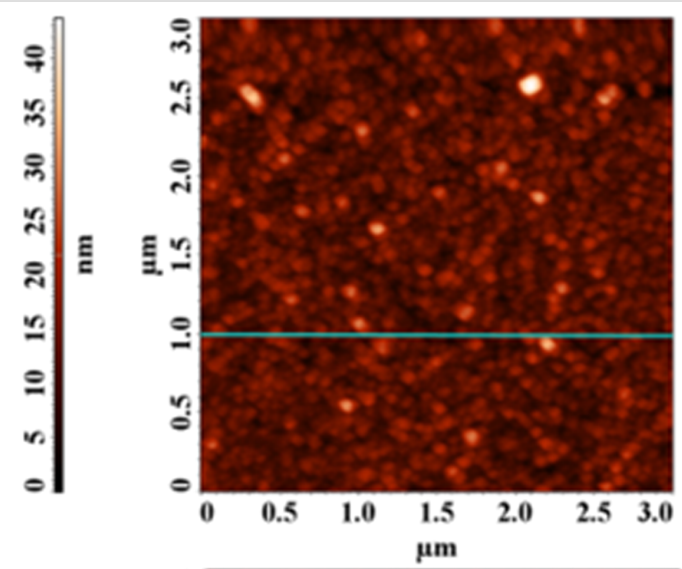
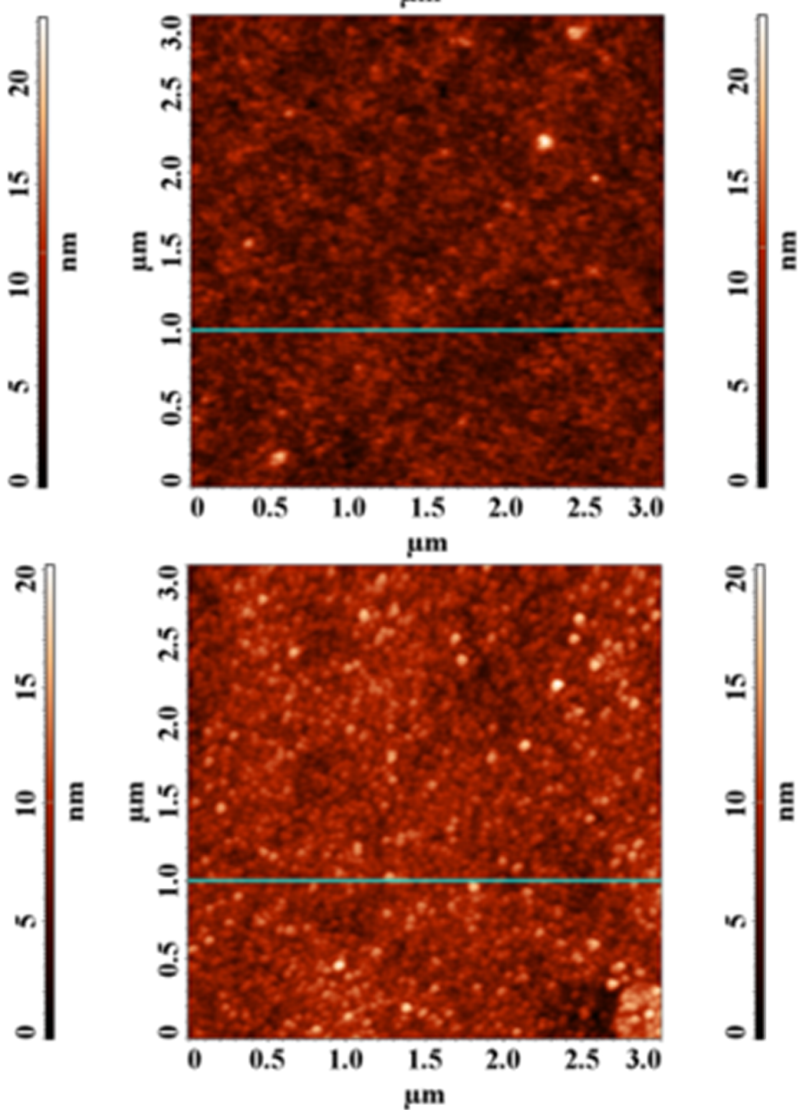

Figure 5: Representative AFM images obtained over $3 \times 3 \mu \mathrm{m}^{2}$ areas of the non-rotaxane 3 (a), 3·TM- $\beta$ CD (b) and 3·TM-yCD (c) polyrotaxanes. 
Table 4: Roughness and grains parameters collected from $3 \times 3 \mu \mathrm{m}^{2}$ AFM images of 3, 3-TM- $\beta C D$ and 3-TM-yCD thin films.

\begin{tabular}{|c|c|c|c|}
\hline \multirow[t]{2}{*}{ Sample } & \multicolumn{3}{|c|}{ Surface roughness } \\
\hline & Sy $(\mathrm{nm})^{\mathrm{a}}$ & $S q(\mathrm{~nm})^{\mathrm{b}}$ & $S a(n m)^{c}$ \\
\hline 3 & 43.7 & 3.73 & 2.73 \\
\hline 3-TM- $\beta C D$ & 21.3 & 1.76 & 1.35 \\
\hline 3·TM-yCD & 23.2 & 1.85 & 1.42 \\
\hline
\end{tabular}

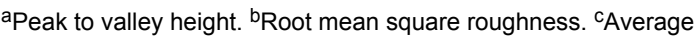
roughness.

As can be seen from Figure 5, the polyrotaxane film surfaces displayed granular morphologies with lower root mean square roughness $(S q)$ and average roughness $(S a)$ surface parameters compared to that of the non-rotaxane counterpart 3 . It should be note that the lower $S q$ and $S a$ values provide microscopic evidence of the changes in the surface topography of the encapsulated compounds.

Taking into account all the information obtained from AFM analysis, it can be concluded that the lower surface parameters clearly evidenced that the encapsulation with chemically-modified CDs leads to better film forming ability with a smoother surface.

\section{Conclusion}

TM- $\beta C D$ or TM- $\gamma C D$ encapsulations of PF backbones lead to distinct improvements in the solubility and transparency of the solid films, increased glass-transition temperatures, enhancements of the surface characteristics. The optical investigations confirmed that the encapsulated compounds exhibited higher PLQE and fluorescence lifetimes. These complex architectures showed interesting electrochemical characteristics, which were consistent with optical and surface morphological results. The slightly lower $\Delta E_{\mathrm{g}}$ value for 3-TM- $\mathbf{\beta C D}$ suggests that the encapsulation have a greater effect on the reduction process, which affects the LUMO values. In addition, HUMO/LUMO energy levels proved that all copolymers are electrochemically accessible in an electroluminescence configuration cell. The present study is significantly valuable and informative as a method to built new conjugated polyrotaxanes by using permodified CD derivatives. Development of new polyrotaxane architectures should be beneficial especially in the field of materials for the generation of active layers in organic electronic devices.

\section{Experimental Materials and methods}

1, 2, tetrakis(triphenylphosphine)palladium $(0)\left[\mathrm{Pd}\left(\mathrm{PPh}_{3}\right)_{4}\right], \beta$ and $\gamma \mathrm{CD}$, bromobenzene $(\mathrm{Br}-\mathrm{Ph})$, dimethylformamide (DMF), dimethyl sulfoxide (DMSO), and quinine sulfate dehydrate in $0.5 \mathrm{M}$ sulfuric acid were purchased from (Sigma-Aldrich) and used as received. $\mathrm{TBAClO}_{4}$ for electrochemical analysis (99.0\%) (Fluka) was used without further purification. Acetonitrile (ACN) (Fischer), DCM, $\mathrm{CHCl}_{3}$, toluene and all other solvents were purchased from commercial sources (Sigma-Aldrich, Fisher) and used without further purification.

${ }^{1} \mathrm{H}$ NMR spectra have been recorded on a Bruker Avance DRX $400 \mathrm{MHz}$ instrument equipped with a $5 \mathrm{~mm}$ QNP direct detection probe and z-gradients. Spectra have been recorded in $\mathrm{CDCl}_{3}$ at room temperature. The chemical shifts are reported as $\delta$ values (ppm) relative to the residual peak of the solvent. The FTIR (KBr pellets) spectra were obtained on a Bruker Vertex 70 spectrophotometer. The molecular weights of copolymers were determined by GPC in THF by using a Water Associates 440 instrument and polystyrene (Pst) calibrating standards. DSC was performed with a Mettler Toledo DSC-12E calorimeter with two repeated heating-cooling cycles at a heating rate of $5{ }^{\circ} \mathrm{C} \cdot \mathrm{min}^{-1}$ under $\mathrm{N}_{2}$ atmosphere. TGA analysis was performed under constant nitrogen flow $\left(20 \mathrm{~mL} \cdot \mathrm{min}^{-1}\right)$ with a heating rate of $10^{\circ} \mathrm{C} \cdot \mathrm{min}^{-1}$ using a Mettler Toledo TGA/SDTA $851 \mathrm{e}$ balance. $\mathrm{UV}-$ vis and fluorescence spectra in $\mathrm{CHCl}_{3}$ solutions were performed using $\mathbf{3}, \mathbf{3} \cdot \mathbf{T M}-\boldsymbol{\beta C D}$ and $\mathbf{3} \cdot \mathbf{T M} \mathbf{M} \boldsymbol{\gamma} \mathbf{C D}$ with the same concentration (either $10^{-1} \mathrm{mg} \cdot \mathrm{mL}^{-1}$ or $10^{-3} \mathrm{mg} \cdot \mathrm{mL}^{-1}$ ) of the 3 cores without macrocyclic molecules. Time-resolved photoluminescence (PL) measurements were performed with a time-correlated single photon counting (TCSPC) spectrometer previously reported [17]. The PLQE was estimated by comparison with a solution of quinine sulfate dehydrate in $0.5 \mathrm{M}$ sulfuric acid of known quantum efficiency, $56 \pm 5 \%$.

CVs were carried out in a three-electrode cell in which Pt ( $1 \mathrm{~mm}$ diameter) was used as a working electrode, a Pt wire as counter-electrode and an Ag wire as pseudo-reference electrode. A $\mathrm{TBAClO}_{4}$ solution $(0.1 \mathrm{M})$ in anhydrous ACN was used as the supporting electrolyte. The set-up was introduced into a glove box and controlled by AUTOLAB PGSTAT 101 (Ecochemie) using NOVA software. The pseudo-reference was calibrated with a $10^{-3} \mathrm{M}$ of Fc solution in ACN. The polymer samples were drop-casted onto the working electrode from a concentrated DCM solution and studied in the interval -2.5 and $+2.0 \mathrm{~V}$ vs Ag wire. Cathodic and anodic scans were performed independently.

The surface profiles of copolymers films were evaluated by AFM measurements. AFM were performed in the tapping mode, using a Solver PRO-M scanning probe microscope (NTMDT, Russia) with commercially available NSG10 cantilever. Films were prepared onto mica substrates by spincoating from $\mathrm{CHCl}_{3}$ solution at $3000 \mathrm{rpm}$ for $60 \mathrm{~s}$ on a 
WS-400B-6NPP-Lite Single Wafer Spin Processor (Laurel Technologies Corporation, USA). Scan areas of $3 \times 3 \mu \mathrm{m}^{2}$, were analyzed with a resolution of $512 \times 512$ pixels. Advancing and receding contact angle measurements were performed by using the drop shape analysis profile device equipped with a tiltable plane (DSA-P, Kruss, Germany). Ultrapure water (Millipore, resistivity $=18 \mathrm{M} \Omega \cdot \mathrm{cm}$ ) or a diiodomethane drop was first deposited on the sample using a variable volume micropipette. The drop volume was set to $15 \mu \mathrm{L}$ for water and $10 \mu \mathrm{L}$ for diiodomethane. In order to perform dynamic contact angle measurements, the sample surface sustaining the drop was tilted at a constant speed $\left(1 \mathrm{deg} \cdot \mathrm{s}^{-1}\right)$ and the images of the drop simultaneously recorded. The advancing contact angle was measured at the front edge of the drop, just before the triple line starts moving. The angle was obtained using the tangent of the drop profile at the triple line. For each sample, contact angles were measured on four samples and three drops per sample. The reported contact angle values correspond to the average of all measurements with an error bar corresponding to the standard deviation.

Synthesis of 2,3,6-tri- $O$-methyl-CD (TM- $\beta C D)$ and 2,3,6-tri$\boldsymbol{O}$-methyl-CD (TM- $\boldsymbol{\gamma}$ CD): TM- $\beta \mathrm{CD}$ and TM- $\gamma \mathrm{CD}$ as macrocyclic molecules were synthesized according to previously reported procedure $[47,48]$.

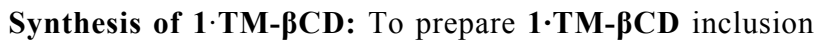
complex, $0.572 \mathrm{~g}(0.4 \mathrm{mmol})$ of TM- $\beta C D$ were dissolved in water $(5.0 \mathrm{~mL})$ and $0.067 \mathrm{~g}(0.2 \mathrm{mmol})$ of 2 were added. The mixture was stirred at room temperature under nitrogen atmosphere for $48 \mathrm{~h}$ to give a turbid dispersion. The water was removed by lyophilization and the complex, as a white powder was used for the preparation of 1-TM- $\mathbf{\beta C D}$. The synthesis of the inclusion complex 1·TM- $\gamma$ CD was performed under similar experimental conditions as those used for the preparation of the

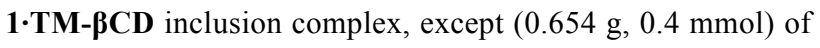
$\mathrm{TM}-\gamma \mathrm{CD}$ was used instead of TM- $\beta C D$.

Synthesis of $3 \cdot T M-\beta C D$ and $3 \cdot T M-\gamma C D$ polyrotaxane copolymers: $\mathbf{1} \cdot \mathbf{T M}-\boldsymbol{\beta C D}(0.639 \mathrm{~g}, 0.2 \mathrm{mmol})$ and $\mathbf{2}(0.115 \mathrm{~g}$, $0.2 \mathrm{mmol}$ ) were dissolved into $6 \mathrm{~mL}$ of toluene in a flask under argon (Ar) protection. The mixture was flushed with Ar several times, and then $1.5 \mathrm{~mL}$ of a $3 \mathrm{M}$ solution of sodium carbonate $\left(\mathrm{Na}_{2} \mathrm{CO}_{3}\right)$ and $18.2 \mathrm{mg}$ of $\left(\mathrm{Ph}_{3} \mathrm{P}\right)_{4} \mathrm{Pd}(0)$, as catalyst dissolved in $4 \mathrm{~mL}$ of degassed toluene were added into the flask. The solution was flushed with Ar again for another three times, and the reaction mixture was protected against light. The oil bath was heated to $90{ }^{\circ} \mathrm{C}$, and the reaction mixture was stirred for $72 \mathrm{~h}$. Then, an excess of $0.005 \mathrm{~g}(0.01 \mathrm{mmol})$ of monomer 2 dissolved in $3 \mathrm{~mL}$ of toluene was added and the reaction was continued for $12 \mathrm{~h}$. Finally, $1.0 \mu \mathrm{L}$ of $\mathrm{Br}-\mathrm{Ph}$ was added as end- capper of the copolymer chain and the reaction was continued overnight. After cooling, the mixture was poured into water and extracted with toluene. The organic extracts were washed with water and dried over magnesium sulfate $\left(\mathrm{MgSO}_{4}\right)$. The toluene solution was concentrated by rotary evaporation and precipitated in $\mathrm{CH}_{3} \mathrm{OH}$. The solid was filtered, dried and purified by Soxhlet extraction with methanol and acetone in succession to remove the oligomers. The polymer was further purified by reprecipitation from concentrated $\mathrm{CHCl}_{3}$ solution with methanol, collected by centrifugation and vacuum dried at $60{ }^{\circ} \mathrm{C}$ to afford 3.TM-BCD (128 mg, 18.8\% yield) as a yellowbrownish solid. ${ }^{1} \mathrm{H}$ NMR (400 MHz, $\left.\mathrm{CDCl}_{3}\right)$ 7.92-7.55 (m, Ha-d and a'-d'), 6.85-6.81 (m, Ph), $5.13(\mathrm{~d}, J=3.6 \mathrm{~Hz}, 7 \mathrm{H}$, $\mathrm{C}(1) \mathrm{H}), 4.11-4.09$ (m, Hg'), 3.88-3.80 (m, 14H, C(5)H, $\mathrm{C}(6) \mathrm{H}), 3.65$ (s, 21H, O(3')- $\left.\mathrm{CH}_{3}\right), 3.62-3.58(\mathrm{~m}, 14 \mathrm{H}, \mathrm{C}(4) \mathrm{H}$, $\mathrm{C}(6) \mathrm{H}), 3.54-3.49$ (m, 28H, C(3)H, O(2')- $\left.\mathrm{CH}_{3}\right), 3.39$ (s, 21H, $\left.\mathrm{O}\left(6^{\prime}\right)-\mathrm{CH}_{3}\right), 3.19(\mathrm{dd}, J=3.6 \mathrm{~Hz}, 7 \mathrm{H}, \mathrm{C}(2) \mathrm{H}), 2.10-1.93(\mathrm{~m}$, Hh), 1.26-1.11 (m, Hi-n), 0.83-0.71 (m, Ho); FTIR (KBr, $\left.\mathrm{cm}^{-1}\right)$ : 3433, 2927, 2853, 1724, 1614, 1459, 1410, 1357, 1159, 1091, 1042, 968, 875, $813 \mathrm{~cm}^{-1}$; GPC (THF, Pst standard): $M_{\mathrm{n}}=24300 \mathrm{~g} \cdot \mathrm{mol}^{-1}, M_{\mathrm{w}} / M_{\mathrm{n}}=1.94$.

3-TM- $\gamma$ CD was synthesized by similar experimental conditions as described for 3-TM- $\mathbf{B C D}$, except that TM- $\gamma \mathrm{CD}$ was used instead of TM- $\beta C D$. 3-TM- $\gamma$ CD polyrotaxane was also obtained as a yellow-brownish solid in a $24.7 \%$ yield. ${ }^{1} \mathrm{H}$ NMR (400 MHz, $\left.\mathrm{CDCl}_{3}\right) 7.92-7.38$ (m, Ha-d and a'-d'), 6.91 (s, Ph), 5.26-5.02 (m, 7H, C(1)H), 4.1-3.25 (m, Hg', C(2-6)H, $\left.\mathrm{O}\left(2^{\prime}, 3^{\prime}, 6^{\prime}\right)-\mathrm{CH}_{3}\right), 2.11$ (s, Hh), 1.11 (s, Hi-n), 0.81 (s, Ho); ${ }^{13} \mathrm{C}$ NMR (100 MHz, $\mathrm{CDCl}_{3}$ ) 151.79-140.10 (C c, e, f, c', e', f'), 132.18-120.21 (C a, b, d, a', b', d'), 98.09 (C1), 82.11 (C2, 4), 71.04 (C5,6 ), 61.07-59.02 (C 2', 3', 6'), 55.41 (C g), 40.49 (C h), 37.18 (Cg'), 31.79 (Ci), 30.05-29.20 (Cj-m), 22.59 (Cn), 14.02 (Co); FTIR (KBr, cm ${ }^{-1}$ ): 3416, 3058, 2923, 2850, 1634, $1610,1457,1405,1373,1291,1095,888,810, \mathrm{~cm}^{-1}$; GPC (THF, Pst standard): $M_{\mathrm{n}}=20100 \mathrm{~g} \cdot \mathrm{mol}^{-1}, M_{\mathrm{w}} / M_{\mathrm{n}}=2.24$.

Synthesis of the non-rotaxane 3 copolymer: The nonrotaxane copolymer 3 was synthesized under similar experimental conditions as those described for 3.TM-BCD or 3-TM- $\gamma$ CD polyrotaxanes, except that free monomer 1 was used instead of 1·TM- $\mathbf{\beta C D}$ or $\mathbf{1} \cdot \mathbf{T M}-\boldsymbol{\gamma} \mathbf{C D}$. The crude polymer $\mathbf{3}$ was collected by filtration and then extracted with a Soxhlet extractor using methanol and acetone. Further the solid was redissolved in $\mathrm{CHCl}_{3}$, precipitated with methanol, collected by filtration and vacuum dried at $50{ }^{\circ} \mathrm{C}$. The copolymer was obtained as an orange solid in a yield of $47.8 \%$. ${ }^{1} \mathrm{H}$ NMR (400 MHz, $\mathrm{CDCl}_{3}$ ) 7.98-7.39 (m, Ha-d and a'-d'), 6.93-6.87 (m, Ph), 4.14-4.06 (m, Hg'), 2.16 (s, Hh), 1.16 (s, Hi-n), 0.86 (s, Ho); ${ }^{13} \mathrm{C}$ NMR (100 MHz, $\left.\mathrm{CDCl}_{3}\right)$ 151.77-140.05 (C c, e, f, c', e', f'), 128.79-120.24 (C a, b, d, a', b', d'), 55.37 (Cg), 
40.47 (Ch), 37.18 (Cg'), 31.79 (Ci), 30.04-29.21 (Cj-m), 22.60 (Cn), $14.06(\mathrm{Co})$; FTIR (KBr, $\left.\mathrm{cm}^{-1}\right): 3438,3024,2954,2922$, 2850, 1605, 1457, 1405, 1378, 1261,1196, 1092, 1023, $810 \mathrm{~cm}^{-1}$; GPC (THF, Pst standard): $M_{\mathrm{n}}=27900 \mathrm{~g} \cdot \mathrm{mol}^{-1}$, $M_{\mathrm{w}} / M_{\mathrm{n}}=1.83$.

\section{Supporting Information}

\section{Supporting Information File 1}

Characterization data of the compounds: The stability constant, FTIR, ${ }^{1} \mathrm{H}$ NMR and ${ }^{13} \mathrm{C}$ NMR spectra of the investigated copolymers.

[http://www.beilstein-journals.org/bjoc/content/ supplementary/1860-5397-11-288-S1.pdf]

\section{Acknowledgements}

This research was supported by a grant of the Romanian National Authority for Scientific Research, CNCS UEFISCDI, project number PN-II-ID-PCE-2011-3-0035. A. F. acknowledges financial support from Institute d'Etude Avancees (IEA), University of Cergy-Pontoise, France. Also, we are grateful to Prof. Sophie Cantin for advancing contact angles of water and diiodomethane measurements. We also thank the EC Seventh Framework Programme (FP7/2007-2013) under Grant Agreement No. 264694 (GENIUS), the EU Horizon 2020 Research and Innovation Programme under Grant Agreement N. 643238 (SYNCHRONICS), as well as the Royal Society and the EPSRC. FC is a Royal Society Wolfson Research Merit Award holder.

\section{References}

1. Chen, H.-Y.; Hou, J.; Zhang, S.; Liang, Y.; Yang, G.; Yang, Y.; Yu, L.; Wu, Y.; Li, G. Nat. Photonics 2009, 3, 649-653. doi:10.1038/nphoton.2009.192

2. Xue, J. Polym. Rev. 2010, 50, 411-419. doi:10.1080/15583724.2010.515766

3. Liang, Y.; Yu, L. Polym. Rev. 2010, 50, 454-473. doi:10.1080/15583724.2010.515765

4. Facchetti, A. Chem. Mater. 2011, 23, 733-758. doi:10.1021/cm102419z

5. Brédas, J.-L.; Norton, J. E.; Cornil, J.; Coropceanu, V. Acc. Chem. Res. 2009, 42, 1691-1699. doi:10.1021/ar900099h

6. Allard, S.; Forster, M.; Souharce, B.; Thiem, H.; Scherf, U. Angew. Chem., Int. Ed. 2008, 47, 4070-4098. doi:10.1002/anie.200701920

7. Leclerc, M. J. Polym. Sci., Part A: Polym. Chem. 2001, 39, 2867-2873. doi:10.1002/pola.1266

8. Ramsdale, C. M.; Barker, J. A.; Arias, A. C.; MacKenzie, J. D.; Friend, R. H.; Greenham, N. C. J. Appl. Phys. 2002, 92, 4266-4270. doi:10.1063/1.1506385

9. Xia, R.; Heliotis, G.; Bradley, D. D. C. Appl. Phys. Lett. 2003, 82, 3599-3601. doi:10.1063/1.1576906
10. Vasilopoulou, M.; Palilis, L. C.; Botsialas, A.; Georgiadou, D. G.;

Bayiati, P.; Vourdas, N.; Petrou, P. S.; Pistolis, G.; Stathopoulos, N. A.; Argitis, P. Phys. Status Solidi C 2008, 5, 3658-3662. doi:10.1002/pssc.200780214

11. Inganäs, O.; Zhang, F.; Andersson, M. R. Acc. Chem. Res. 2009, 42, 1731-1739. doi:10.1021/ar900073s

12. Scherf, U.; List, E. J. W. Adv. Mater. 2002, 14, 477-487. doi:10.1002/1521-4095(20020404)14:7<477::AID-ADMA477>3.0.CO;2 $-9$

13. Grimsdale, A. C.; Chan, K. L.; Martin, R. E.; Jokisz, P. G.; Holmes, A. B. Chem. Rev. 2009, 109, 897-1091. doi:10.1021/cr000013v

14. Lee, S. K.; Ahn, T.; Cho, N. S.; Lee, J.-I.; Jung, Y. K.; Lee, J.; Shim, H. K. J. Polym. Sci., Part A: Polym. Chem. 2007, 45, 1199-1209. doi:10.1002/pola.21892

15. Zhu, Y.; Gibbons, K. M.; Kulkarni, A. P.; Jenekhe, S. A. Macromolecules 2007, 40, 804-813. doi:10.1021/ma062445z

16. Farcas, A.; Resmerita, A.-M.; Stefanache, A.; Balan, M.; Harabagiu, V. Beilstein J. Org. Chem. 2012, 8, 1505-1514. doi:10.3762/bjoc.8.170

17. Farcas, A.; Tregnago, G.; Resmerita, A.-M.; Taleb Dehkordi, S.; Cantin, S.; Goubard, F.; Aubert, P.-H.; Cacialli, F. J. Polym. Sci., Part A: Polym. Chem. 2014, 52, 460-471. doi:10.1002/pola.27034

18. Jahanfar, M.; Tan, Y.; Tsuchiya, K.; Shimomura, T.; Ogino, K. Open J. Org. Polym. Mater. 2013, 3, 41-45. doi:10.4236/ojopm.2013.32007

19. Farcas, A.; Resmerita, A.-M.; Aubert, P.-H.; Stoica, I.; Farcas, F.; Airinei, A. Beilstein J. Org. Chem. 2014, 10, 2145-2156. doi:10.3762/bjoc. 10.222

20. Farcas, A.; Janietz, S.; Harabagiu, V.; Guegan, P.; Aubert, P.-H. J. Polym. Sci., Part A: Polym. Chem. 2013, 51, 1672-1683. doi:10.1002/pola.26546

21. Mativetsky, J. M.; Kastler, M.; Savage, R. C.; Gentilini, D.; Palma, M.; Pisula, W.; Müllen, K.; Samorí, P. Adv. Funct. Mater. 2009, 19, 2486-2494. doi:10.1002/adfm.200900366

22. Chu, Z.; Wang, D.; Zhang, C.; Fan, X.; Tang, Y.; Chen, L.; Zou, D. Macromol. Rapid Commun. 2009, 30, 1745-1750. doi:10.1002/marc.200900268

23. Yang, C.; Song, H.-S.; Liu, D.-B. J. Mater. Sci. 2013, 48, 6719-6727. doi:10.1007/s10853-013-7473-8

24. Lim, S.-F.; Friend, R. H.; Rees, I. D.; Li, J.; Ma, Y.; Robinson, K.; Holmes, A. B.; Hennebicq, E.; Beljonne, F.; Cacialli, F. Adv. Funct. Mater. 2005, 15, 981-988. doi:10.1002/adfm.200400457

25. Calzaferri, G.; Huber, S.; Mass, H.; Minkowski, C. Angew. Chem., Int. Ed. 2003, 42, 3732-3758. doi:10.1002/anie.200300570

26. Sozzani, P.; Comotti, A.; Bracco, S.; Simonutti, R. Angew. Chem., Int. Ed. 2004, 43, 2792-2797. doi:10.1002/anie.200353479

27. Frampton, M. J.; Claridge, T. D. W.; Latini, G.; Broveli, S.; Cacialli, F.; Anderson, H. L. Chem. Commun. 2008, 2797-2799. doi:10.1039/b803335h

28. Cacialli, F.; Wilson, J. S.; Michels, J. J.; Daniel, C.; Silva, C.; Friend, R. H.; Severin, N.; Samorì, P.; Rabe, J. P.; O'Connell, M. J.; Taylor, P. N.; Anderson, H. L. Nat. Mater. 2002, 1, 160-164. doi:10.1038/nmat750

29. Wenz, G.; Han, B.-H.; Müller, A. Chem. Rev. 2006, 106, 782-817. doi:10.1021/cr970027+

30. Frampton, M. J.; Anderson, H. L. Angew. Chem., Int. Ed. 2007, 46, 1028-1064. doi:10.1002/anie.200601780 
31. Harada, A.; Hashidzume, A.; Yamaguchi, H.; Takashima, Y. Chem. Rev. 2009, 109, 5974-6023. doi:10.1021/cr9000622

32. Petrozza, A.; Brovelli, S.; Michels, J. J.; Anderson, H. L.; Friend, R. H.; Silva, C.; Cacialli, F. Adv. Mater. 2008, 20, 3218-3223. doi:10.1002/adma.200800007

33. Oddy, F. E.; Brovelli, S.; Stone, M. T.; Klotz, E. J. F.; Cacialli, F.; Anderson, H. L. J. Mater. Chem. 2009, 19, 2846-2852. doi:10.1039/b821950h

34. Farcas, A.; Jarroux, N.; Ghosh, I.; Guégan, P.; Nau, W. M.; Harabagiu, V. Macromol. Chem. Phys. 2009, 210, 1440-1449. doi:10.1002/macp.200900140

35. Zalewski, L.; Wykes, M.; Brovelli, S.; Bonini, M.; Breiner, T.; Kastler, M.; Dötz, F.; Beljonne, D.; Anderson, H. L.; Cacialli, F.; Samorì, P. Chem. - Eur. J. 2010, 16, 3933-3941. doi:10.1002/chem.200903353

36. Zalewski, L.; Brovelli, S.; Bonini, M.; Mativetsky, J. M.; Wykes, M.; Orgiu, E.; Breiner, T.; Kastler, M.; Dötz, F.; Meinardi, F.; Anderson, H. L.; Beljonne, D.; Cacialli, F.; Samorì, P. Adv. Funct. Mater. 2011, 21, 834-844. doi:10.1002/adfm.201001135

37. Farcas, A.; Ghosh, I.; Nau, W. M. Chem. Phys. Lett. 2012, 535 120-125. doi:10.1016/j.cplett.2012.03.069

38. Brovelli, S.; Sforazzini, G.; Serri, M.; Winroth, G.; Suzuki, K.; Meinardi, F.; Anderson, H. L.; Cacialli, F. Adv. Funct. Mater. 2012, 22 , 4284-4291. doi:10.1002/adfm.201200786

39. Szejtli, J. Chem. Rev. 1998, 98, 1743-1753. doi:10.1021/cr970022c

40. Dsouza, R. N.; Pischel, U.; Nau, W. M. Chem. Rev. 2011, 111, 7941-7980. doi:10.1021/cr200213s

41. Wenz, G. Adv. Polym. Sci. 2009, 222, 204-254. doi:10.1007/12_2008_13

42. González-Gaitano, G.; Rodríguez, P.; Isasi, J. R.; Fuentes, M.; Tardajos, G.; Sánchez, M. J. Inclusion Phenom. Macrocyclic Chem. 2002, 44, 101-105. doi:10.1023/A:1023065823358

43. Farcas, A.; Jarroux, N.; Guégan, P.; Fifere, A.; Pinteala, M.; Harabagiu, V. J. Appl. Polym. Sci. 2008, 110, 2384-2392. doi:10.1002/app.28760

44. Farcas, A.; Ghosh, I.; Jarroux, N.; Harabagiu, V.; Guégan, P.; Nau, W. M. Chem. Phys. Lett. 2008, 465, 96-101. doi:10.1016/j.cplett.2008.09.058

45. Farcas, A.; Jarroux, N.; Harabagiu, V.; Guégan, P. Eur. Polym. J. 2009, 45, 795-803. doi:10.1016/j.eurpolymj.2008.11.047

46. Farcas, A.; Jarroux, N.; Guegan, P.; Harabagiu, V.; Melnig, V. J. Optoelectron. Adv. Mater. 2007, 9, 3484-3488.

47. Nakazono, K.; Takashima, T.; Arai, T.; Koyama, Y.; Takata, T. Macromolecules 2010, 43, 691-696. doi:10.1021/ma902161d

48. Stefanache, A.; Silion, M.; Stoica, I.; Fifere, A.; Harabagiu, V.; Farcas, A. Eur. Polym. J. 2014, 50, 223-234. doi:10.1016/j.eurpolymj.2013.11.001

49. Chen, S. H.; Su, A. C.; Su, C. H. Macromolecules 2005, 38, 379-385 doi:10.1021/ma048162t

50. Brovelli, S.; Meinardi, F.; Winroth, G.; Fenwick, O.; Sforazzini, G.; Frampton, M. J.; Zalewski, L.; Levitt, J. A.; Marinello, F.; Schiavuta, P.; Suhling, K.; Anderson, H. L.; Cacialli, F. Adv. Funct. Mater. 2010, 20, 272-280. doi:10.1002/adfm.200901764

51. Liu, B.; Yu, W. -L.; Lai, Y.-H.; Huang, W. Chem. Mater. 2001, 13, 1984-1991. doi:10.1021/cm0007048

52. de Leeuw, D. M.; Simenon, M. M. J.; Brown, A. R.; Einerhand, R. E. F. Synth. Met. 1997, 87, 53-59. doi:10.1016/S0379-6779(97)80097-5

53. Metri, N.; Sallenave, X.; Plesse, C.; Beouch, L.; Aubert, P.-H.; Goubard, F.; Chevrot, C.; Sini, G. J. Phys. Chem. C 2012, 116, 3765-3772. doi:10.1021/jp2098872
54. Al-Ibrahim, M.; Roth, H.-K.; Schroedner, M.; Konkin, A.; Zhokhavets, U.; Gobsch, G.; Scharff, P.; Sensfuss, S. Org. Electron. 2005, 6, 65-77. doi:10.1016/j.orgel.2005.02.004

55. Cantin, S.; Bouteau, M.; Benhabib, F.; Perrot, F. Colloids Surf., A 2006, 276, 107-115. doi:10.1016/j.colsurfa.2005.10.025

\section{License and Terms}

This is an Open Access article under the terms of the Creative Commons Attribution License

(http://creativecommons.org/licenses/by/2.0), which permits unrestricted use, distribution, and reproduction in any medium, provided the original work is properly cited.

The license is subject to the Beilstein Journal of Organic Chemistry terms and conditions: (http://www.beilstein-journals.org/bjoc)

The definitive version of this article is the electronic one which can be found at: doi:10.3762/bjoc. 11.288 